\title{
Mechanisms behind bottom-up effects: Eutrophication increases fecundity by shortening the interspawning interval in stickleback
}

\author{
Anne Saarinen ${ }^{1}$, Ulrika Candolin ${ }^{\text {Corresp. } 1}$ \\ ${ }^{1}$ Organismal and Evolutionary Biology, University of Helsinki, Helsinki, Finland \\ Corresponding Author: Ulrika Candolin \\ Email address: ulrika.candolin@helsinki.fi
}

Anthropogenic eutrophication is altering aquatic environments by promoting primary production. This influences the population dynamics of consumers through bottom-up effects, but the underlying mechanisms and pathways are not always clear. To evaluate and mitigate effects of eutrophication on ecological communities, more research is needed on the underlying factors. Here we show that anthropogenic eutrophication increases population fecundity in the threespine stickleback (Gasterosteus aculeatus) by increasing the number of times females reproduce - lifetime fecundity - rather than instantaneous fecundity. When we exposed females to nutrient-enriched waters with enhanced algal growth, their interspawning interval shortened but the size of their egg clutches, or the size of their eggs, did not change. The shortening of the interspawning interval was probably caused by higher food intake, as algae growth promotes the growth of preferred prey populations. Enhanced female lifetime fecundity could increase offspring production and, hence, influence population dynamics. In support of this, earlier studies show that more offspring are emerging in habitats with denser algae growth. Thus, our results stress the importance of considering lifetime fecundity, in addition to instantaneous fecundity, when investigating the impact of human-induced eutrophication on population processes. At a broader level, our results highlight the importance of following individuals over longer time spans when evaluating the pathways and processes through which environmental changes influence individual fitness and population processes. 
1 Mechanisms behind bottom-up effects: Eutrophication increases fecundity by

2 shortening the interspawning interval in stickleback

3

4

Anne Saarinen and Ulrika Candolin*

5

6

Organismal and Evolutionary Biology, University of Helsinki, PO Box 65, 00014 Helsinki, Finland

7

8 *Author for correspondence:

$9 \quad$ Ulrika Candolin

10 Email: ulrika.candolin@helsinki.fi

11

12 Ulrika Candolin Orcid ID: 0000-0001-8736-7793 


\section{Abstract}

14 Anthropogenic eutrophication is altering aquatic environments by promoting primary production.

15 This influences the population dynamics of consumers through bottom-up effects, but the underlying mechanisms and pathways are not always clear. To evaluate and mitigate effects of eutrophication on ecological communities, more research is needed on the underlying factors. Here we show that anthropogenic eutrophication increases population fecundity in the threespine stickleback (Gasterosteus aculeatus) by increasing the number of times females reproduce - lifetime fecundity rather than instantaneous fecundity. When we exposed females to nutrient-enriched waters with enhanced algal growth, their interspawning interval shortened but the size of their egg clutches, or the size of their eggs, did not change. The shortening of the interspawning interval was probably caused by higher food intake, as algae growth promotes the growth of preferred prey populations. Enhanced female lifetime fecundity could increase offspring production and, hence, influence population dynamics. In support of this, earlier studies show that more offspring are emerging in habitats with denser algae growth. Thus, our results stress the importance of considering lifetime fecundity, in addition to instantaneous fecundity, when investigating the impact of human-induced eutrophication on population processes. At a broader level, our results highlight the importance of following individuals over longer time spans when evaluating the pathways and processes through which environmental changes influence individual fitness and population processes.

32 Keywords: Egg production, environmental change, foraging, population dynamics, reproduction, trophic interactions 


\section{Introduction}

Human activities are altering habitats around the world at an unprecedented rate and scale. A growing human-induced problem in aquatic ecosystems is eutrophication, the enrichment of ecosystems with nutrients (Smith 2003). It promotes primary production, which in turn has a range of secondary effects on ecosystems, such as the accumulation of decomposing organic matter that uses up oxygen, the promotion of toxic algal blooms, and the proliferation of ephemeral algae in coastal systems (Le Moal et al. 2019; Paerl et al. 2014). These changes cause the decline of some species, while others profit and increase in abundance (Levin et al. 2009; O'Neil et al. 2012). Yet, the factors that determine whether a species profits or suffers from eutrophication are poorly known (Di Carvalho \& Wickham 2019; Rigosi et al. 2014). This gap in our knowledge is due to the intricate effects of eutrophication on species - it influences species not only directly but also indirectly through ecological interactions and feedbacks among species (Candolin et al. 2018; Hoover \& Tylianakis 2012; Wootton 1994). In addition, other human-induced disturbances can modify the effects of eutrophication, such as climate change (Buma 2015; Jackson et al. 2016; Russell et al. 2009), coastal construction (Kraufvelin et al. 2010) and mesopredator release (Kraufvelin et al. 2020; Östman et al. 2016). Thus, to unravel the effects of eutrophication on species, the underlying mechanisms and pathways need to be identified and delineated.

In the Baltic Sea, nutrient concentrations started to increase in the 1950s because of human activities, reached a top in the 1980s and 1990s, after which the concentrations stabilised and even declined in many parts of the sea (Andersen et al. 2017; Gustafsson et al. 2012). However, in the Gulf of Finland, nutrient concentrations have continued to be high (Andersen et al. 2017). In addition, a range of other perturbations have occurred in the area that could interact with eutrophication, such as climate change (particularly warming), the overfishing of top predators, and the invasion of alien species (Casini et al. 2008; Meier et al. 2019; Ojaveer et al. 2010; Rutgersson et al. 2014). Yet, how these different disturbances influence biodiversity, directly and indirectly, and their individual and combined effects, are poorly known (Meier et al. 2019; Vehmaa et al. 2018). This is hampering our ability to evaluate and mitigate the effects of eutrophication on the ecosystem, calling for more research into the topic.

The abundance of the threespine stickleback, Gasterosteus aculeatus, has increased in the Gulf of Finland during the last decades, as well as in other parts of the Baltic Sea (Bergström et al. 2015; 
64

Candolin et al. 2016b; Candolin \& Voigt 2020; Olsson et al. 2019). The increase has been attributed to a top-down effect from the decline of top-predators (Eriksson et al. 2011; Ljunggren et al. 2010). However, recent research indicates that a top-down effect alone cannot explain the increase, but that other factors must have contributed (Bergström et al. 2015). One such factor could be eutrophication and a bottom-up effect through increased algal growth and prey abundance. This is plausible as the threespine stickleback spends the summer in shallow coastal waters where eutrophication has enhanced the growth of filamentous algae (Bäck et al. 2000; Candolin 2004; Gubelit \& Kovalchuk 2010; Kraufvelin et al. 2006; Rinne et al. 2018; Rinne et al. 2011) and thereby the abundance of prey, such as gammarids and other grazers (Candolin et al. 2016a; Olafsson et al. 2013; Salovius \& Kraufvelin 2004), the preferred prey of the threespine stickleback in coastal waters (Candolin et al. 2016a; Jakubaviciute et al. 2017). In support of a bottom-up effect, the population growth of the stickleback in the Gulf of Finland correlates with increased population fecundity in terms of the proportion of gravid females in the population (Candolin \& Voigt 2020). Females develop several sequential clutches of eggs during the breeding season and could profit from eutrophication in terms of increased food intake and, thus, fecundity. Males establish territories and build nests to which they attract several females to spawn, while females spend most of their time foraging (Wootton 1984). After spawning, the female leaves the nest and the male alone cares for the eggs until hatching (Wootton 1984). Males do not benefit from increased food abundance in terms of improved body condition (Candolin \& Voigt 2020), as they reduce feeding while engaged in nesting activities (Wootton 1984). Instead, males benefit from denser algal growth in term of shelter from predators and less interference from nest destroying and eggs stealing conspecifics (Candolin 2004; Candolin et al. 2014; Candolin \& Voigt 1998). Thus, improved male parenting ability in eutrophied habitats could ensure that the increased female fecundity results in increased offspring production.

The possibility that increased female fecundity has promoted offspring production in eutrophied habitats is supported by an increased number of fry emerging in spawning areas with a denser growth of algae (Candolin et al. 2014). The increased offspring production could have contributed to the growth of the population, depending on the survival of the fry to the adult stage. However, whether such a bottom-up effect occurs - through increased female fecundity - is still an open question. Yet, determining the causes of the population growth is of paramount importance considering the key role that this mesopredator plays in the ecosystem. It influences the abundance 
95 96

of other species, both directly and indirectly, and affects ecological process such as energy flow and nutrient cycling (Candolin 2019; Des Roches et al. 2013; Jakobsen et al. 2003; Limberger et al. 2019). Thus, more information is needed on the factors and processes that regulate the abundance of stickleback to improve our understanding of the causes and consequence of the changes occurring in the ecosystem, as well as to develop mitigation and adaptation strategies to minimize risks of largescale changes.

We investigated if eutrophication increases female fecundity during the spawning season and, thus, if eutrophication could increase offspring production. To determine the effect of eutrophication on fecundity, we exposed females to high and low nutrient levels during the breeding season - which increases algae growth and prey availability - and recorded effects on the number and size of egg clutches produced.

\section{Materials and methods}

We caught threespine stickleback before the breeding season in early May from a bay in the outer archipelago of the Northern Baltic Proper $\left(59^{\circ} 50^{\prime} \mathrm{N}, 23^{\circ} 15^{\prime} \mathrm{E}\right)$ using minnow traps. We housed the fish in large holding tanks at a photoperiod of $18 \mathrm{~L}: 6 \mathrm{D}$, a temperature of $18^{\circ} \mathrm{C}$, and a salinity of $0.6 \%$ to reflect natural conditions in the field. We moved females showing signs of sexual maturation (swollen abdomens and darker stripes on their lateral sides) to experimental tanks (28 I), one female to each tank, to follow their development of eggs. Before transfer, we measured their standard body length $( \pm 1 \mathrm{~mm})$, and after the first spawning event, their body weight $( \pm 0.1 \mathrm{~g})$. Body weight was not recorded before spawning as handling can cause females to release their eggs. The tanks were kept under natural light and temperature conditions, in several parallel lines on an outdoor platform. To ensure a healthy environment, sea water was slowly flowing through the tanks (about $100 \mathrm{ml} / \mathrm{min}$ ) between 2 and 4 pm each day. All tanks received fresh sea water that had not been through other experimental tanks. A net at the outflow (mesh size $0.2 \mathrm{~mm}$ ) prevented organisms from escaping the tanks. The net was cleaned from algae every morning and evening.

To simulate habitats differing in eutrophication state and, thus, in the density of filamentous algae and associated prey, we exposed the females to one of two treatments: low or high algae density, with $50 \mathrm{~g}$ or $150 \mathrm{~g}$ respectively of the filamentous alga Cladophora glomerata evenly distributed over 
124 the bottom of the tanks, together with associated natural invertebrate fauna. The densities

125 correspond to natural low and high algae densities in the field (Candolin et al. 2016a). We

126 manipulated algae and prey densities directly, rather than allowing algae and prey populations to

127 gradually grow under two different nutrient levels, because of time constraints. The algae, with

128 invertebrates, had been collected from the same area as the stickleback, and the algal filaments

129 attached to plastic nets $(35 \times 30 \mathrm{~cm}$, mesh size $1 \mathrm{~cm})$ at the bottom of the tanks through sewing.

130 Before being placed in the tanks, the nets with algae had been held in a large common pool for one

131 day to homogenize the distribution of invertebrates among the nets. Some grazers could have

132 escaped during collection and transfer, and we consequently added five Gammarus sp. (about 10

$133 \mathrm{~mm}$ ) to the low-algae density treatment, and 15 Gammarus sp. to the high-algae density treatment,

134 i.e. three times more prey to the tank with three times more algae. The additions were based on

135 prior investigations of the amount of prey in the algae and the number lost when handling the algae,

136 with the combined abundance of algae and prey reflecting conditions in high and low eutrophied

137 habitats (Candolin et al. 2016a). To ensure that the difference in algae density was maintained

138 throughout the experiment, we added nutrients to the high-algae density tanks, by adding nutrients

139 to the water flowing through the tanks during the $2 \mathrm{~h}$ of flow through (a nutrient mixture containing

$1400.046 \mathrm{~g}$ of nitrogen/l and $0.036 \mathrm{~g}$ of phosphorous/l), while no nutrients were added to the low-algae

141 density tanks. The nutrient addition should not influence the stickleback directly, only indirectly

142 through increased algae and prey growth, as stickleback do not feed on nutrients. The used nutrient

143 concentrations have been found to promote algal growth in prior research (Heuschele et al. 2009;

144 Järvenpää \& Lindström 2004). Sea water naturally contains nutrients, which maintained the algal

145 growth at natural low levels in the low-algae tanks.

146 We observed the females daily to record their fecundity state. As soon as a female was ready to

147 spawn, based on a distended belly and a dilated urogenital papilla, we allowed her to spawn her eggs

148 in the nest of a male. Males had been collected from the same site as the females, and allowed to

149 build nests in individual tanks (10 I), following methods in Candolin (1997). When the male had

150 fertilised the eggs, we removed both the male and the female and returned the female to her tank to

151 continue to develop eggs. We collected the eggs from the nest $2 \mathrm{~h}$ later when the eggs had

152 hardened, and counted the number in the clutch. To measure egg size, we measured the diameter of

15310 eggs using a microscope with a micrometre eyepiece. Females release all ovulated eggs during a

154 spawning (Wootton 1984). We recorded female body weight after each spawning.

Peer] reviewing PDF | (2020:04:47488:1:0:NEW 22 May 2020) 
155 We allowed the females to produce as many egg clutches as they could until the end of July when the 156 breeding season ended. All but five females died towards the end of the experiment (three survived 157 in the low-algae treatment, and two in the high-algae treatment), as stickleback in the present 158 population breed during one breeding season after which they die (Candolin 2000). We recorded 159 mean interbreeding interval (days), number of egg clutches produced, mean number of eggs in each 160 clutch, and mean diameter of eggs in each clutch. To measure the amount of zooplankton left in the 161 tank at the end of the experiment, we took a 1 I water sample, filtered it through a $200 \mu \mathrm{m}$ mesh net, 162 and counted the number of zooplankton under a stereo microscope. To measure the amount of 163 filamentous algae left in the tank, we detached the algae from the net and measured the wet weight. 164 To measure the amount of benthos left in the algae, we collected all invertebrates visible to the eye 165 (mainly amphipods, chironomids, gastropods, isopods, and caddisfly larvae), dried them on blotting 166 paper, and measured their total weight.

167 We used 20 females per each treatment. We used ANOVA to analyse the data and checked the assumptions of the test before analyses. Females in the two treatments did not differ in body length at the start of the experiment $\left(F_{1,38}=0.04, P=0.85\right)$ or in body weight after the first spawning $\left(F_{1,38}=\right.$ $0.04, P=0.84)$.

The study was conducted according to national guidelines and meets the terms of the regional ethics committee, the National Animal Experimental Board in Finland.

\section{Results}

Females in the high-algae treatment completed more breeding cycles and had shorter interbreeding intervals than females in the low-algae treatment (table 1). The two groups did not differ in the number of eggs in the clutches or in the size of the eggs (table 1).

177 Females in the two algae treatments did not differ in the loss of body weight after each breeding cycle, or over the experimental days (table 1), or in the number of days in the experiment (table 1). algae treatment (table 2). Similarly, the amount of prey organisms was higher in the high-algae treatment at the end of the experiment, for both zooplankton and benthos (table 2). 


\section{Discussion}

184 Our high-algae density treatment increased the lifetime fecundity of threespine stickleback females, 185 but did not change their instantaneous fecundity. Females produced more egg clutches at higher 186 algae density by shortening their interspawning interval, but they did not alter the size of their egg 187 clutches or the size of their eggs. Because females in the present population complete only one 188 breeding season after which most of them die (Candolin 2000), as was also found in this experiment, 189 the produced egg clutches represent the lifetime egg production of the females.

190 The increase in egg production rate was most likely caused by the increased prey availability and, 191 thus, higher food intake, as the abundance of prey was higher in denser algae growth. High density of 192 algae promotes the population growth of many benthic organisms, such as gammarids (Kraufvelin 193 2007; Kraufvelin \& Salovius 2004; Kraufvelin et al. 2006; Olafsson et al. 2013; Salovius \& Kraufvelin 194 2004), which are the dominant prey species of the stickleback in coastal waters (Candolin et al. 195 2016a; Jakubaviciute et al. 2017). In support of an impact of increased prey availability on lifetime 196 fecundity, earlier laboratory studies have found increased food ration to shorten the interspawning 197 interval of females and increase the number of egg clutches they produce (Ali \& Wootton 1999; 198 Fletcher \& Wootton 1995; Wootton \& Fletcher 2009). However, the interspawning intervals in the earlier laboratory studies - which used enchytraeid worms as food - were much shorter (about 4 days at high food ration, figure 2 in Ali \& Wootton (1999)) than in our mesocosm experiment with natural prey and algae densities (15.5 days on average). This indicates that females in our experiment were not producing eggs at their maximum capacity. Limited prey availability and energy spent on searching for, catching, handling, and digesting the natural prey probably limited egg production rate.

205 206

The cause of the lack of an effect of the high-algae treatment on clutch size could be physiological and morphological restrictions of females. Moreover, evolutionary processes could have favoured the production of several smaller clutches rather than a few large ones in order to spread out the risk of failed reproduction. Males may cannibalise eggs laid by females (Candolin \& Vlieger 2013), and producing many sequential egg clutches - laid at different times into different nests - may spread out the risk of egg cannibalism, and, hence, be a more successful strategy than spawning many eggs into a few nests. 
212 An alternative, not mutually exclusive, explanation for the increased female lifetime fecundity

213 compared to the increase prey abundance is that females felt safer in denser algal growth and,

214 hence, experienced lower stress levels. This could have reduced energy use and allowed more energy

215 to be allocated to egg production. In support of this, dense algal growth decreases aggressive

216 interactions among individuals (Candolin et al. 2014) and reduces perceived predation risk from

217 piscivorous fishes and birds (Ajemian et al. 2015; Candolin \& Voigt 2001; Sohel \& Lindström 2015).

218 Thus, both increased energy intake and reduced energy use could have contributed to the increased

219 lifetime fecundity. However, lower stress levels are unlikely to be the main cause of the increased

220 lifetime fecundity, as females in high and low algae density did not differ in body condition after each

221 spawning, or at the end of the spawning season. High stress levels in vertebrates have a stronger

222 negative effect on body condition than on fecundity (Crespi et al. 2013), and no such effect was

223 evident in our experiment. Moreover, both algae treatments reflected natural algae densities that

224 the species has adapted to and, hence, should not constitute overly stressful conditions (Candolin

225 2004). Yet, to decisively determine the relative contribution of increased energy intake and reduced

226 energy use on lifetime fecundity, prey abundance and algae density need to be separately

227 manipulated, which requires a much larger experiment than the present one.

228 The increased female lifetime fecundity could have further consequences for population dynamics by

229 increasing offspring production. However, the effect on the population depends on the spawning

230 success of the females and the survival of the offspring both pre- and posthatching. Earlier studies

231 show that more nests are available and embryo survival is higher in denser algal growth (Candolin et

232 al. 2014), probably because of reduced aggressive interactions among parenting males and fewer

233 intrusions by nest raiders and egg thieves (Candolin \& Vlieger 2013). Thus, more juveniles are

234 emerging in densely vegetated habitats (Candolin et al. 2014). However, whether the increased

235 offspring production influences the growth of stickleback populations depends on density-dependent

236 processes later in life, such as the risk of predation and the transmission of infections (Murdoch

237 1994; Rose et al. 2001). More research is consequently needed before any form conclusions can be

238 drawn about the impact of increased female fecundity on population growth.

239 The degree to which the documented effect of eutrophication on female lifetime fecundity reflects

240 processes in other eutrophied habitats is unknown, as we are aware of no other longitudinal studies

241 on lifetime fecundity of individual stickleback females. In populations where females breed during

242 multiple years (Wootton 1984), females could save resources for survival until the next breeding

Peer] reviewing PDF | (2020:04:47488:1:0:NEW 22 May 2020) 
243

244

245

246

247

248

249

250

251

252

253

254

255

256

257

258

259

260

261

262

263

264

265

266

267

268

269

270

271

season rather than investing in multiple breeding cycles per season. Thus, an interesting question is whether females in population with predominantly one breeding season could alter their strategy towards investment into survival and multiple breeding seasons, through phenotypic plasticity or evolutionary changes. This could increase the size of the adult population - through extended longevity of females - and, hence, alter the dynamics of the population. Thus, different reproductive responses to eutrophication could, have different effects on population structure and dynamics.

The influence of eutrophication on populations varies among species, with some species benefitting while others are disfavoured, altering the species composition of communities (Hossain et al. 2019; Jeppesen et al. 2005; Mehner et al. 2005). The threespine stickleback appears to be a winner in profiting from both increased offspring production (Candolin et al. 2014) and reduced predation pressure (Bergström et al. 2015), possibly at the expense of other species (Candolin 2019). For instance, the increased abundance of stickleback could reduce the abundance of piscivores, the predators of stickleback, as stickleback prey on the larvae of piscivores (Byström et al. 2015). This could further promote the decline of top predators (Bergström et al. 2016; Casini et al. 2008;

Ljunggren et al. 2010) and result in a feedback loop where the decline of predators further promotes the growth of the stickleback population. Thus, changes in species abundances can have further consequences for ecological and evolutionary processes (Candolin 2019; Johannesson et al. 2011; Norkko et al. 2019), which emphasises the importance of evaluating the effects of eutrophication on populations, including the mechanisms and pathways behind the effects.

\section{Conclusion}

Our results show that eutrophication and increased algae growth enhances lifetime fecundity of threespine stickleback females, but not their instantaneous fecundity. The increased lifetime fecundity could have contributed to the increased offspring production in the investigated population, but whether this has contributed to the growth of the population deserves more investigations. More broadly, our results stress the importance of considering effects of eutrophication on lifetime fecundity - not only on instantaneous fecundity - when evaluating the impact of eutrophication on population dynamics and community composition. 
272

273

274

275

276

277

278

279

280

281

282

283

284

285

286

287

288

289

290

291

292

293

294

295

296

297

298

299

300

301

302

303

304

305

306

307

308

309

310

311

312

313

314

315

Acknowledgments We thank Marita Kuusinen for assistance with the experiment.

\section{References}

Ajemian MJ, Sohel S, and Mattila J. 2015. Effects of turbidity and habitat complexity on antipredator behavior of three-spined sticklebacks (Gasterosteus aculeatus). Environmental Biology of Fishes 98:45-55. 10.1007/s10641-014-0235-x

Ali M, and Wootton RJ. 1999. Effect of variable food levels on reproductive performance of breeding female three-spined sticklebacks. Journal of Fish Biology 55:1040-1053. 10.1006/jfbi.1999.1114

Andersen JH, Carstensen J, Conley DJ, Dromph K, Fleming-Lehtinen V, Gustafsson BG, Josefson AB, Norkko A, Villnäs A, and Murray C. 2017. Long-term temporal and spatial trends in eutrophication status of the Baltic Sea. Biological Reviews 92:135-149. 10.1111/brv.12221

Bergström L, Heikinheimo O, Svirgsden R, Kruze E, Lozys L, Lappalainen A, Saks L, Minde A, Dainys J, Jakubaviciute $\mathrm{E}$, Ådjers K, and Olsson J. 2016. Long term changes in the status of coastal fish in the Baltic Sea. Estuarine Coastal and Shelf Science 169:74-84. 10.1016/j.ecss.2015.12.013

Bergström U, Olsson J, Casini M, Eriksson BK, Fredriksson R, Wennhage H, and Appelberg M. 2015. Stickleback increase in the Baltic Sea - A thorny issue for coastal predatory fish. Estuarine Coastal and Shelf Science 163:134-142.

Buma B. 2015. Disturbance interactions: characterization, prediction, and the potential for cascading effects. Ecosphere 6:15. 10.1890/es15-00058.1

Byström P, Bergström U, Hjalten A, Stahl S, Jonsson D, and Olsson J. 2015. Declining coastal piscivore populations in the Baltic Sea: Where and when do sticklebacks matter? Ambio 44:S462-S471. 10.1007/s13280-015-0665-5

Bäck S, Lehvo A, and Blomster J. 2000. Mass occurrence of unattached Enteromorpha intestinalis on the Finnish Baltic Sea coast. Annales Botanici Fennici 37:155-161.

Candolin U. 1997. Predation risk affects courtship and attractiveness of competing threespine stickleback males. Behavioral Ecology and Sociobiology 41:81-87.

Candolin U. 2000. Changes in expression and honesty of sexual signalling over the reproductive lifetime of sticklebacks. Proceedings of the Royal Society B-Biological Sciences 267:2425-2430.

Candolin U. 2004. Effects of algae cover on egg acquisition in male three-spined stickleback. Behaviour 141:1389-1399.

Candolin U. 2019. The threespine stickleback (Gasterosteus aculeatus) as a modifier of ecological disturbances. Evolutionary Ecology Research 20:167-191.

Candolin U, Bertell E, and Kallio J. 2018. Environmental disturbance alters the ecological impact of an invading shrimp. Functional Ecology 32:1370-1378. 10.1111/1365-2435.13078

Candolin U, Johanson A, and Budria A. 2016a. The influence of stickleback on the accumulation of primary production: a comparison of field and experimental data. Estuaries and Coasts 39:248257. 10.1007/s12237-015-9984-9

Candolin U, Nieminen A, and Nyman J. 2014. Indirect effects of human-induced environmental change on offspring production mediated by behavioural responses. Oecologia 174:87-97. 10.1007/s00442-013-2752-2

Candolin U, Tukiainen I, and Bertell E. 2016b. Environmental change disrupts communication and sexual selection in a stickleback population. Ecology 97:969-979. 10.1890/15-1090.1

Candolin U, and Vlieger L. 2013. Estimating the dynamics of sexual selection in changing environments. Evolutionary Biology 40:589-600. 
316

Candolin U, and Voigt HR. 1998. Predator-induced nest site preference: safe nests allow courtship in sticklebacks. Animal Behaviour 56:1205-1211.

Candolin U, and Voigt HR. 2001. Correlation between male size and territory quality: consequence of male competition or predation risk? Oikos 95:225-230.

Candolin U, and Voigt HR. 2020. Population growth correlates with increased fecundity in three-spined stickleback populations in a human-disturbed environment. Aquatic Sciences 82:21.

Casini M, Lovgren J, Hjelm J, Cardinale M, Molinero JC, and Kornilovs G. 2008. Multi-level trophic cascades in a heavily exploited open marine ecosystem. Proceedings of the Royal Society BBiological Sciences 275:1793-1801. 10.1098/rspb.2007.1752

Crespi EJ, Williams TD, Jessop TS, and Delehanty B. 2013. Life history and the ecology of stress: how do glucocorticoid hormones influence life-history variation in animals? Functional Ecology 27:93106. 10.1111/1365-2435.12009

Des Roches S, Shurin JB, Schluter D, and Harmon LJ. 2013. Ecological and evolutionary effects of stickleback on community structure. Plos One 8. 10.1371/journal.pone.0059644

Di Carvalho JA, and Wickham SA. 2019. Simulating eutrophication in a metacommunity landscape: an aquatic model ecosystem. Oecologia 189:461-474. 10.1007/s00442-018-4319-8

Eriksson BK, Sieben K, Eklöf J, Ljunggren L, Olsson J, Casini M, and Bergström U. 2011. Effects of altered offshore food webs on coastal ecosystems emphasize the need for cross-ecosystem management. Ambio 40:786-797. 10.1007/s13280-011-0158-0

Fletcher DA, and Wootton RJ. 1995. A hierarchical response to differences in ration size in the reproductive performance of female three-spined sticklebacks. Journal of Fish Biology 46:657668.

Gubelit YI, and Kovalchuk NA. 2010. Macroalgal blooms and species diversity in the Transition Zone of the eastern Gulf of Finland. Hydrobiologia 656:83-86. 10.1007/s10750-010-0425-2

Gustafsson BG, Schenk F, Blenckner T, Eilola K, Meier HEM, Muller-Karulis B, Neumann T, Ruoho-Airola T, Savchuk OP, and Zorita E. 2012. Reconstructing the development of Baltic Sea eutrophication 1850-2006. Ambio 41:534-548. 10.1007/s13280-012-0318-x

Heuschele J, Mannerla M, Gienapp P, and Candolin U. 2009. Environment-dependent use of mate choice cues in sticklebacks. Behavioral Ecology 20:1223-1227. 10.1093/beheco/arp123

Hoover SER, and Tylianakis JM. 2012. Species interactions. In: Candolin U, and Wong BBM, eds. Behavioural responses to a changing world: mechanisms and consequences. Oxford: Oxford University Press, 129-142.

Hossain M, Arhonditsis GB, Hoyle JA, Randall RG, and Koops MA. 2019. Nutrient management and structural shifts in fish assemblages: Lessons learned from an Area of Concern in Lake Ontario. Freshwater Biology 64:967-983. 10.1111/fwb.13278

Jackson MC, Loewen CJG, Vinebrooke RD, and Chimimba CT. 2016. Net effects of multiple stressors in freshwater ecosystems: a meta-analysis. Global Change Biology 22:180-189. 10.1111/gcb.13028

Jakobsen TS, Hansen PB, Jeppesen E, Gronkjaer P, and Sondergaard M. 2003. Impact of three-spined stickleback Gasterosteus aculeatus on zooplankton and chl a in shallow, eutrophic, brackish lakes. Marine Ecology Progress Series 262:277-284. 10.3354/meps262277

Jakubaviciute E, Bergström U, Eklöf JS, Haenel Q, and Bourlat SJ. 2017. DNA metabarcoding reveals diverse diet of the three-spined stickleback in a coastal ecosystem. Plos One 12:16. 10.1371/journal.pone.0186929

Jeppesen E, Sondergaard M, Jensen JP, Havens KE, Anneville O, Carvalho L, Coveney MF, Deneke R, Dokulil MT, Foy B, Gerdeaux D, Hampton SE, Hilt S, Kangur K, Kohler J, Lammens E, Lauridsen TL, Manca M, Miracle MR, Moss B, Noges P, Persson G, Phillips G, Portielje R, Schelske CL, Straile D, Tatrai I, Willen E, and Winder M. 2005. Lake responses to reduced nutrient loading - an analysis 
of contemporary long-term data from 35 case studies. Freshwater Biology 50:1747-1771. 10.1111/j.1365-2427.2005.01415.x

Johannesson K, Smolarz K, Grahn M, and Andre C. 2011. The future of Baltic Sea populations: local extinction or evolutionary rescue? Ambio 40:179-190. 10.1007/s13280-010-0129-x

Järvenpää $M$, and Lindström K. 2004. Water turbidity by algal blooms causes mating system breakdown in a shallow-water fish, the sand goby Pomatoschistus minutus. Proceedings of the Royal Society of London Series B-Biological Sciences 271:2361-2365.

Kraufvelin P. 2007. Responses to nutrient enrichment, wave action and disturbance in rocky shore communities. Aquatic Botany 87:262-274. 10.1016/j.aquabot.2007.06.011

Kraufvelin P, Christie H, and Gitmark JK. 2020. Top-down release of mesopredatory fish is a weaker structuring driver of temperate rocky shore communities than bottom-up nutrient enrichment. Marine Biology 167:20. 10.1007/s00227-020-3665-3

Kraufvelin P, Lindholm A, Pedersen MF, Kirkerud LA, and Bonsdorff E. 2010. Biomass, diversity and production of rocky shore macroalgae at two nutrient enrichment and wave action levels. Marine Biology 157:29-47. 10.1007/s00227-009-1293-z

Kraufvelin P, and Salovius S. 2004. Animal diversity in Baltic rocky shore macroalgae: can Cladophora glomerata compensate for lost Fucus vesiculosus? Estuarine Coastal and Shelf Science 61:369378. 10.1016/j.ecss.2004.06.006

Kraufvelin P, Salovius S, Christie H, Moy FE, Karez R, and Pedersen MF. 2006. Eutrophication-induced changes in benthic algae affect the behaviour and fitness of the marine amphipod Gammarus locusta. Aquatic Botany 84:199-209. 10.1016/j.aquabot.2005.08.008

Le Moal M, Gascuel-Odoux C, Menesguen A, Souchon Y, Etrillard C, Levain A, Moatar F, Pannard A, Souchu P, Lefebvre A, and Pinay G. 2019. Eutrophication: A new wine in an old bottle? Science of the Total Environment 651:1-11. 10.1016/j.scitotenv.2018.09.139

Levin LA, Ekau W, Gooday AJ, Jorissen F, Middelburg JJ, Naqvi SWA, Neira C, Rabalais NN, and Zhang J. 2009. Effects of natural and human-induced hypoxia on coastal benthos. Biogeosciences 6:20632098. 10.5194/bg-6-2063-2009

Limberger R, Birtel J, Peter H, Catalan N, da Silva Faroas D, Best RJ, Brodersen J, Burgmann H, and Matthews B. 2019. Predator-induced changes in dissolved organic carbon dynamics. Oikos in press.

Ljunggren L, Sandström A, Bergström U, Mattila J, Lappalainen A, Johansson G, Sundblad G, Casini M, Kaljuste O, and Eriksson BK. 2010. Recruitment failure of coastal predatory fish in the Baltic Sea coincident with an offshore ecosystem regime shift. Ices Journal of Marine Science 67:15871595. 10.1093/icesjms/fsq109

Mehner T, Diekmann M, Bramick U, and Lemcke R. 2005. Composition of fish communities in German lakes as related to lake morphology, trophic state, shore structure and human-use intensity. Freshwater Biology 50:70-85. 10.1111/j.1365-2427.2004.01294.x

Meier HEM, Eilola K, Almroth-Rosell E, Schimanke S, Kniebusch M, Höglund A, Pemberton P, Liu Y, Väli G, and Saraiva S. 2019. Disentangling the impact of nutrient load and climate changes on Baltic Sea hypoxia and eutrophication since 1850. Climate Dynamics 53:1145-1166. 10.1007/s00382-0184296-y

Murdoch WW. 1994. Population regulation in theory and practice. Ecology 75:271-287. $10.2307 / 1939533$

Norkko J, Pilditch CA, Gammal J, Rosenberg R, Enemar A, Magnussond M, Granberg ME, Lindgren JF, Agrenius $S$, and Norkko A. 2019. Ecosystem functioning along gradients of increasing hypoxia and changing soft-sediment community types. Journal of Sea Research 153:12. 10.1016/j.seares.2019.101781 
410

411

412

413

414

415

416

417

418

419

420

421

422

423

424

425

426

427

428

429

430

431

432

433

434

435

436

437

438

439

440

441

442

443

444

445

446

447

448

449

450

451

452

453

454

455
O'Neil JM, Davis TW, Burford MA, and Gobler CJ. 2012. The rise of harmful cyanobacteria blooms: The potential roles of eutrophication and climate change. Harmful Algae 14:313-334. 10.1016/j.hal.2011.10.027

Ojaveer H, Jaanus A, MacKenzie BR, Martin G, Olenin S, Radziejewska T, Telesh I, Zettler ML, and Zaiko A. 2010. Status of biodiversity in the Baltic Sea. Plos One 5:19. 10.1371/journal.pone.0012467

Olafsson E, Aarnio K, Bonsdorff E, and Arroyo NL. 2013. Fauna of the green alga Cladophora glomerata in the Baltic Sea: density, diversity, and algal decomposition stage. Marine Biology 160:2353-2362. 10.1007/s00227-013-2229-1

Olsson J, Jakubaviciute E, Kaljuste O, Larsson N, Bergström U, Casini M, Cardinale M, Hjelm J, and Byström P. 2019. The first large-scale assessment of three-spined stickleback (Gasterosteus aculeatus) biomass and spatial distribution in the Baltic Sea. Ices Journal of Marine Science 76:1653-1665. 10.1093/icesjms/fsz078

Paerl HW, Hall NS, Peierls BL, and Rossignol KL. 2014. Evolving paradigms and challenges in estuarine and coastal eutrophication dynamics in a culturally and climatically stressed world. Estuaries and Coasts 37:243-258. 10.1007/s12237-014-9773-x

Rigosi A, Carey CC, Ibelings BW, and Brookes JD. 2014. The interaction between climate warming and eutrophication to promote cyanobacteria is dependent on trophic state and varies among taxa. Limnology and Oceanography 59:99-114. 10.4319/lo.2014.59.1.0099

Rinne H, Korpinen S, Mattila J, and Salovius-Lauren S. 2018. Functionality of potential macroalgal indicators in the northern Baltic Sea. Aquatic Botany 149:52-60. 10.1016/j.aquabot.2018.05.006

Rinne H, Salovius-Lauren S, and Mattila J. 2011. The occurrence and depth penetration of macroalgae along environmental gradients in the northern Baltic Sea. Estuarine Coastal and Shelf Science 94:182-191. 10.1016/j.ecss.2011.06.010

Rose KA, Cowan JH, Winemiller KO, Myers RA, and Hilborn R. 2001. Compensatory density dependence in fish populations: importance, controversy, understanding and prognosis. Fish and Fisheries 2:293-327. 10.1046/j.1467-2960.2001.00056.x

Russell BD, Thompson JAI, Falkenberg LJ, and Connell SD. 2009. Synergistic effects of climate change and local stressors: $\mathrm{CO} 2$ and nutrient-driven change in subtidal rocky habitats. Global Change Biology 15:2153-2162. 10.1111/j.1365-2486.2009.01886.x

Rutgersson A, Jaagus J, Schenk F, and Stendel M. 2014. Observed changes and variability of atmospheric parameters in the Baltic Sea region during the last 200 years. Climate Research 61:177-190. $10.3354 / \mathrm{cr} 01244$

Salovius S, and Kraufvelin P. 2004. The filamentous green algae Cladophora glomerata as a habitat for littoral macro-fauna in the northern Baltic Sea. Ophelia 58:65-78.

Smith VH. 2003. Eutrophication of freshwater and coastal marine ecosystems - a global problem. Environ Sci Poll Res 10:126-139.

Sohel S, and Lindström K. 2015. Algal turbidity reduces risk assessment ability of the three-spined stickleback. Ethology 121:548-555. 10.1111/eth.12370

Vehmaa A, Katajisto T, and Candolin U. 2018. Long-term changes in a zooplankton community reveated by the sediment archive. Limnology and Oceanography 63:2126-2139.

Wootton JT. 1994. The nature and consequences of indirect effects in ecological communities. Annual Review of Ecology and Systematics 25:443-466. 10.1146/annurev.es.25.110194.002303

Wootton RJ. 1984. The functional biology of sticklebacks. London: Croom Helm.

Wootton RJ, and Fletcher DA. 2009. Effect of spawning number and ration on reproductive performance of the batch-spawning three-spined stickleback Gasterosteus aculeatus. Journal of Fish Biology 75:618-629. 10.1111/j.1095-8649.2009.02311.x

Peer] reviewing PDF | (2020:04:47488:1:0:NEW 22 May 2020) 
456 Östman Ö, Eklöf J, Eriksson BK, Olsson J, Moksnes PO, and Bergström U. 2016. Top-down control as

457 important as nutrient enrichment for eutrophication effects in North Atlantic coastal

458 ecosystems. Journal of Applied Ecology 53:1138-1147. 10.1111/1365-2664.12654

459

460 


\section{Table 1 (on next page)}

The impact of eutrophication and the density of filamentous algae on the production of eggs, loss of body weight, and time in the experiment, of threespine stickleback females 
1 Table 1. The impact of eutrophication and the density of filamentous algae on the production of eggs,

2 loss of body weight, and time in the experiment, of threespine stickleback females

\begin{tabular}{llllll}
\hline & Low algae & High algae & & \\
\cline { 2 - 3 } & Mean \pm SE & Mean \pm SE & & $F_{1,38}$ & $\mathrm{P}$ \\
\hline Number of breeding cycles & $3.6 \pm 0.2$ & $5.0 \pm 0.3$ & & 15.48 & $<0.001$ \\
Interbreeding interval, days & $19.1 \pm 1.0$ & $15.5 \pm 0.8$ & 7.60 & 0.009 \\
Clutch size, egg number & $153.6 \pm 6.0$ & $149.2 \pm 6.0$ & 0.27 & 0.60 \\
Egg diameter, mm & $1.77 \pm 0.02$ & $1.76 \pm 0.02$ & 0.11 & 0.74 \\
Loss of weight after spawning, \% & $9.45 \pm 1.49$ & $7.85 \pm 1.00$ & 0.80 & 0.38 \\
Total loss of weight, \% & $9.10 \pm 3.42$ & $7.70 \pm 0.93$ & 0.16 & 0.70 \\
Experimental days & $61.6 \pm 2.69$ & $66.25 \pm 2.38$ & 1.64 & 0.21 \\
\hline
\end{tabular}

ANOVA was used to analyse the data 
Table 2 (on next page)

Conditions in the experimental tanks at the end of the experiment 
3

4 Table 2. Conditions in the experimental tanks at the end of the experiment

\begin{tabular}{lllll}
\hline & Low density & High density & & \\
\cline { 2 - 3 } & Mean \pm SE & Mean \pm SE & $F_{1,38}$ & P \\
\hline Filamentous algae, g & $69.50 \pm 3.02$ & $175.96 \pm 4.98$ & 333.65 & $<0.001$ \\
Number of zooplankton I-1 & $24.15 \pm 2.82$ & $79.00 \pm 8.94$ & 34.22 & $<0.001$ \\
Benthos, g & $0.80 \pm 0.28$ & $2.91 \pm 0.49$ & 14.21 & 0.001
\end{tabular}

ANOVA was used to analyse the data

5

6

7 